\title{
The insolvable problem; survival effect of lymphadenectomy in advanced stage ovarian cancer
}

\author{
Mehmet Sait Bakır®, Özer Birge ${ }^{\circledR}$, Ceyda Karadag $₫$, Selen Doğan $₫$, \\ Hasan Aykut Tuncer(D, Tayup Simsek (1) \\ Akdeniz University Faculty of Medicine, Antalya, Turkey
}

\begin{abstract}
Objectives: In this study, we aimed to evaluate the effect of systemic lymphadenectomy on overall and progression free survival in advanced stage of ovarian cancer.

Material and methods: The data of ovarian cancer patients who had been admitted to our clinic between March 2008 and December 2019 were collected retrospectively. The patients who had received neo-adjuvant chemotherapy (NACT), those having undergone interval surgery, those who had non-epithelial ovarian cancer, those with residual tumour larger than $1 \mathrm{~cm}$ and those with stage I-IIA were excluded from the study.

Results: A total of 241 patients with inclusion criteria were included in the study. While 169 patients $(70.1 \%)$ had undergone systemic lymphadenectomy (SLND), 72 (29.9\%) had not. Lymph node involvement was present in 105 out of 169 patients (62.1\%) who had undergone SLND. There was no statistically significant difference between the groups in terms of SLND and lymph node involvement for both progression free survival (PFS) and overall survival (OS) $(p=0.577, p=0.493, p=0.481$, $p=0.849$ respectively). When subgroup analysis was performed according to the residual tumor amount, we could not find any statistically significant difference in both PFS and OS in terms of SLND and lymph node involvement in RO (complete resection) group ( $p=0.057, p=0.917, p=0.106$ and $p=0.980$ respectively). We found similar results for patients in the $\mathrm{R} 1$ (optimal resection) group.

Conclusions: It was found that performing systemic lymphadenectomy had no effect on both progressive and overal survival. It should be kept in mind that the increasing number of malignant lymph nodes removed could have a therapeutic effect in OS. Large numbers of randomized clinical trials are required to enlighten this debatable issue that has been continuing, particularly in the recent two decades.
\end{abstract}

Key words: ovarian cancer; lymphadenectomy; residual tumour; lymph node count

Ginekologia Polska 2021; 92, 12: 829-836

\section{INTRODUCTION}

Approximately $1.3 \%$ of women will develop ovarian cancer during their lifetime and most of them will be in advanced stage at the time of diagnosis [1]. According to the GLOBOCAN 2018 data, 295.414 new ovarian cancer cases (1.6\%) and 184.799 ovarian cancer-related deaths were reported among all cancers. It is the $8^{\text {th }}$ leading cause of female cancers with an incidence of $3.4 \%$ and a mortality rate of 4.4\% [2]. As target therapy, Bavesizumab (anti-vascular endothelial growth factor antibody) has been recommended in combination with chemotherapy (CT) or as maintenance therapy $[3,4]$. Despite these treatment modalities, ovarian cancer remains the female genital cancer with the high- est mortality rate [5]. The main treatment of ovarian cancer is reducing the tumour load either completely (complete $=\mathrm{R} 0$ ) or to below $1 \mathrm{~cm}$ (optimal = R1) and administration of six cycles of adjuvant carboplatin + paclitaxel chemotherapy as the post-surgery tumour amount is the most important prognostic factor [6, 7]. Lymphatic metastasis is also very common beside peritoneal spread. Therefore, lymphatic involvement has been accepted as a poor prognostic factor, in both early and advanced stage disease [8]. The lymphatic involvement rate has been reported as $60-72 \%$ in the literature [9]. Radical lymphadenectomy leads to severe morbidity $[10,11]$. While some retrospective studies report that

\footnotetext{
Corresponding author:

Mehmet Sait Bakır

Akdeniz University Faculty of Medicine, Antalya, Turkey

e-mail: sabakcil@gmail.com
} 
lymphadenectomy contributes to progression-free survival (PFS) and overall survival (OS) [6, 12], another randomized study has reported that it does not contribute to OS [13]. Although included in FIGO (The International Federation of Gynaecology and Obstetrics), lymphadenectomy was not shown to have a contribution to OS in advanced stage epithelial ovarian cancer patients who had undergone complete resection in a recent randomized controlled LION study [11].

In the present study, it was aimed to present the results of our patients who had been diagnosed and who had undergone lymphadenectomy in the last 14 years under the light of the literature, which presents conflicting results about lymphadenectomy that is an important part of the surgical treatment of ovarian cancer.

\section{MATERIAL AND METHODS}

The data of ovarian cancer patients who had been admitted to our clinic between March 2008 and December 2019 were collected retrospectively. The study was evaluated by the Akdeniz University Faculty of Medicine Clinical Research Ethics Committee and was approved under the decision number KAEK-436. A routinely informed consent was taken from all participants. The patients who had received neo-adjuvant chemotherapy (NACT), those who had undergone interval surgery, those who had non-epithelial ovarian cancer, those with residual tumour larger than $1 \mathrm{~cm}$ and those with stage 1-2A were excluded from the study. The study's inclusion criteria were patients with epithelial ovarian cancer, stage $2 b-4$ (including resectable stage $4 b$ ), who had undergone primary debulking surgery and had no second primary tumour. A total of 241 patients who fulfilled the inclusion criteria were included. All patients were classified according to the FIGO surgical staging system and operated by an expert surgeon in the gynaecological oncology field. All patients were compared in terms of age, tumor grade, histology, recurrence, lymph node involvement, number and location of malignant lymph nodes, number of malignant lymph nodes, residual tumour amount, death and follow-up time. The abdomen was accessed through an infra-umbilical median incision and total abdominal hysterectomy and bilateral salpingo-oophorectomy were carried out, an abdominal cytology specimen was obtained, total omentectomy \pm systemic lymphadenectomy (SLND) was carried out, small intestine and/or colon resection and splenectomy were performed, and the required surgical procedures were carried out depending on tumoral involvement.

While systemic pelvic LND included the lymph nodes and the neighbouring fat tissues up to the mesial part of the common iliac artery beginning from the circumflex iliac vein including the lymph nodes in the obturator space, the para-aortic LND included the lymph nodes and the neighbouring fat tissues around the vena cava inferior in the cephalic direction from the mesial part of the common iliac artery and anterior side of the aorta, inferior and superior parts of the inferior mesenteric artery and at the level of the left renal vein. All the patients included in our study received six cycles of the standard adjuvant systemic chemotherapy at the time. The patients received carboplatin + paclitaxel chemotherapy as adjuvant therapy post-operatively and followed-up once every three months during the first two years, and once every six months during the following three years for recurrence. After completing the five-year follow-up, the gynaecological oncology and medical oncology clinics follow all patients for the rest of their lives. The patients were divided into two groups as those who had undergone systemic lymphadenectomy and those who had not. The patients were divided into three groups according to the number of removed lymph nodes, while 1-20 lymph nodes were removed in the patients in Group 1, 21-40 LN were removed in Group 2 and more than LNs were removed 41 in Group 3.

\section{Statistical analysis}

Descriptive statistics were expressed as mean, standard deviation, median, min-max values and frequencies. The statistical significance between the categorical variables was tested with the Chi-square test. The parametric and non-parametric tests were used for the numerical data depending on the normality distribution. The influence of clinical and pathological factors on overall survival was tested with the Kaplan-Meier log rank test. The effect of various prognostic factors on the survey alone or together was examined using the uni-variate or the multi-variate cox proportional hazards model. Statistical analyses were carried out using the SPSS ver. 23. $P$ values in all tests were two-tailed and a $p$ value of $<0.05$ was accepted as statistically significant.

\section{RESULTS}

The median age of the patients who had undergone SLND was 51.5 years (range 37-85); the median was 54 (range 30-79) for patients who had not undergone SLND ( $p: 0.001$ ). The median PFS was 16.0 months and the median OS was 65.3 months. While 169 patients $(70.1 \%)$ had undergone SLND, 72 (29.9\%) had not. The clinical and pathological characteristics of the patients have been presented in Table 1.

The largest number of patients was in Stage $3(85 \%)$ and there was a statistically significant relationship between the tumour stage and SLND (p: 0.003). A total of 161 (66.8\%) patients had serous histology followed by endometrioid type (13.6\%). Of the patients, 220 had Grade 2-3 tumour. Fifty-five (22.8\%) out of 62 (25.7\%) patients who had undergone complete resection (R0) had undergone SLND. While 


\begin{tabular}{|c|c|c|c|c|c|}
\hline & & $\begin{array}{l}\text { LND (+) } \\
\text { n: } 169\end{array}$ & $\begin{array}{l}\text { LND (-) } \\
\mathrm{n}: 72\end{array}$ & $\begin{array}{l}\text { Total } \\
\mathrm{n}: 241\end{array}$ & p value \\
\hline Age (median) & & 51.5 (range: 37-85) & 54 (range: $30-79$ ) & 50 & 0.001 \\
\hline Stage & $\begin{array}{l}2 b \\
3 \\
4\end{array}$ & $\begin{array}{l}16(6.6 \%) \\
147(60.99 \%) \\
6(2.4 \%)\end{array}$ & $\begin{array}{l}3(1.2 \%) \\
58(24 \%) \\
11(4.55)\end{array}$ & $\begin{array}{l}19(7.8 \%) \\
205(85.06) \\
17(7 \%)\end{array}$ & 0.003 \\
\hline Histology & $\begin{array}{l}\text { Serous } \\
\text { Endometrioid } \\
\text { Clear } \\
\text { Mucinous } \\
\text { Mixed type }\end{array}$ & $\begin{array}{l}104(43.1 \%) \\
28(11.6 \%) \\
8(3.3 \%) \\
3(1.2 \%) \\
26(10.7 \%)\end{array}$ & $\begin{array}{l}57(23.6 \%) \\
5(2 \%) \\
4(1.6 \%) \\
2(0.8 \%) \\
4(1.6 \%)\end{array}$ & $\begin{array}{l}161(66.8 \%) \\
33(13.6 \%) \\
12(4.9 \%) \\
5(2 \%) \\
30(12.3 \%)\end{array}$ & 0.041 \\
\hline Grade & $\begin{array}{l}1 \\
2 \\
3\end{array}$ & $\begin{array}{l}16(6.6 \%) \\
19(7.8 \%) \\
134(55.6)\end{array}$ & $\begin{array}{l}5(2 \%) \\
5(2 \%) \\
62(25.7 \%)\end{array}$ & $\begin{array}{l}21(8.7 \%) \\
24(9.9 \%) \\
196(81.3 \%)\end{array}$ & 0.451 \\
\hline Residual tumour & $\begin{array}{l}\text { R0 } \\
\text { R1 }(\leq 1 \mathrm{~cm})\end{array}$ & $\begin{array}{l}55(22.8 \%) \\
114(47.2 \%)\end{array}$ & $\begin{array}{l}7(2.9 \%) \\
65(26.9 \%)\end{array}$ & $\begin{array}{l}62(25.7 \%) \\
179(74.2 \%)\end{array}$ & 0.001 \\
\hline Recurrence & $\begin{array}{l}\text { Yes } \\
\text { No }\end{array}$ & $\begin{array}{l}140(58.1 \%) \\
29(12.0 \%)\end{array}$ & $\begin{array}{l}58(24.1 \%) \\
14(5.8 \%)\end{array}$ & $\begin{array}{l}198(82.2 \%) \\
43(17.8 \%)\end{array}$ & 0.672 \\
\hline Status & $\begin{array}{l}\text { Dead } \\
\text { Alive }\end{array}$ & $\begin{array}{l}134(55.6 \%) \\
35(14.5 \%)\end{array}$ & $\begin{array}{l}54(22.4 \%) \\
18(7.5 \%)\end{array}$ & $\begin{array}{l}188(78 \%) \\
53(22 \%)\end{array}$ & 0.462 \\
\hline Number of LN & $\begin{array}{l}1-20 \\
21-40 \\
41<\end{array}$ & $\begin{array}{l}13(7.7 \%) \\
49(29 \%) \\
107(63.3 \%)\end{array}$ & & $169(100 \%)$ & 0.001 \\
\hline LN involvement & $\begin{array}{l}\text { Yes } \\
\text { No }\end{array}$ & $\begin{array}{l}105(62.1 \%) \\
64(37.9 \%)\end{array}$ & & $169(100 \%)$ & 0.002 \\
\hline $\begin{array}{l}\text { Location of LN } \\
\text { involvement }\end{array}$ & $\begin{array}{l}\text { Pelvic } \\
\text { Para-aortic } \\
\text { Pelvic+para-aortic }\end{array}$ & $\begin{array}{l}17(16.2 \%) \\
27(25.7 \%) \\
61(58.1 \%)\end{array}$ & & 105 (100\%) & 0.001 \\
\hline $\begin{array}{l}\text { Number of malignant } \\
\text { LN }\end{array}$ & $\begin{array}{l}0 \\
1-5 \\
6-10 \\
11<\end{array}$ & $\begin{array}{l}64(37.9 \%) \\
61(36.1 \%) \\
12(7.1 \%) \\
32(18.9 \%)\end{array}$ & & $169(100 \%)$ & 0.001 \\
\hline $\begin{array}{l}\text { Duration of follow-up } \\
\text { [months] }\end{array}$ & & & & $\begin{array}{l}57(0.53-121) \\
14.5(0.17-121)\end{array}$ & \\
\hline
\end{tabular}

LND - lymphadenectomy; LN —lymph node

114 (47.2\%) out of 179 (74.2\%) patients who had undergone optimal (R1) resection had undergone SLND, 64 (26.9\%) had not. Lymph node involvement was present in 105 out of 169 patients $(62.1 \%)$ who had undergone SLND, and the median number of metastatic LN was 4 (min: 1-max: 62). Pelvic + para-aortic LN involvement was detected in 61 patients. While the median number of removed LNs was 46 (min: 9-max: 95), 41 or more LNs were removed in 107 (63.3\%) patients. A weak and significant correlation was determined between the number of $L N s$ and positive LNs ( $r$ : $0.344, r 2=0.118$ and $p<0.001$ ). The median duration of follow-up was 57 (range: 0.53-121) months. While 188 (78\%) patients passed away, 53 (22\%) survived. Recurrence developed in 198 (82.2\%) patients and no recurrence developed in 43 (17.8\%) (Tab. 1). There was no statistically significant difference between the two groups in terms of recurrence and death ( $p: 0.672$ and p: 0.462, respectively). Both PFS ( $p<0.001)$ and OS ( $<0.001)$ were observed to impair as the tumour stage increased (Tab. 2). When the grade and histology were evaluated, there was no difference between the groups with regard to survival ( $p>0.05)$. While the median PFS was 18 months in the SLND group, it was 13.1 months in patients who had not undergone SLND ( $p=0.577)$. While the median PFS was 18.0 months in 105 patients who had LN involvement, it was 18.7 months in patients who did not have $L N$ involvement ( $p=0.493$ ). However, no difference was found in OS in patients who had undergone SLND and who had LN involvement $(p=0.481$, $p=0.849$, respectively). Survival has been presented in Figure 1. It was observed that the number of removed LNs had no effect on PFS and OS ( $p=0.092, p=0.242$, respectively).

It was found that lymph node metastasis location had no effect on both PFS and OS ( $p: 0.267$ and p: 0.751 respectively). The patients were allocated to three groups according to the number of malignant LNs (Group 1: 1-5, Group 2: 6-10, Group 3: > 10). Statistically significant relationship was 


\begin{tabular}{|c|c|c|c|c|c|c|c|c|c|c|}
\hline & & \multirow{3}{*}{$\mathbf{n}$} & \multicolumn{4}{|c|}{ PFS } & \multicolumn{4}{|c|}{ OS } \\
\hline & & & \multirow{2}{*}{ mo } & \multicolumn{2}{|c|}{$\mathrm{Cl} \% 95$} & \multirow{2}{*}{$\mathbf{p}$} & \multirow{2}{*}{ mo } & \multicolumn{2}{|c|}{$\mathrm{Cl} \% 95$} & \multirow{2}{*}{$\mathbf{p}$} \\
\hline & & & & Lower & Upper & & & Lower & Upper & \\
\hline Age [years] & $\begin{array}{l}\leq 50 \\
>50\end{array}$ & $\begin{array}{l}75 \\
166\end{array}$ & $\begin{array}{l}19.2 \\
14.9\end{array}$ & $\begin{array}{l}15.6 \\
13.0\end{array}$ & $\begin{array}{l}22.8 \\
16.7\end{array}$ & 0.185 & $\begin{array}{l}78.0 \\
63.0\end{array}$ & $\begin{array}{l}68.5 \\
56.9\end{array}$ & $\begin{array}{l}87.4 \\
69.0\end{array}$ & 0.209 \\
\hline Stage & $\begin{array}{l}2 b \\
3 a 1,3 a 2,3 b, 3 c \\
4 a, 4 b\end{array}$ & $\begin{array}{l}19 \\
205 \\
17\end{array}$ & $\begin{array}{l}27.0 \\
16.6 \\
8.0\end{array}$ & $\begin{array}{l}12.6 \\
12.7 \\
3.9\end{array}$ & $\begin{array}{l}59.3 \\
18.6 \\
12.0\end{array}$ & 0.001 & $\begin{array}{l}98.5 \\
68.0 \\
22.7\end{array}$ & $\begin{array}{l}72.3 \\
60.9 \\
19.7\end{array}$ & $\begin{array}{l}124.7 \\
75.0 \\
25.7\end{array}$ & 0.001 \\
\hline Grade & $\begin{array}{l}-1 \\
-2 \\
-3\end{array}$ & $\begin{array}{l}21 \\
24 \\
196\end{array}$ & $\begin{array}{l}21.3 \\
14.0 \\
15.9\end{array}$ & $\begin{array}{l}20.6 \\
11.7 \\
13.1\end{array}$ & $\begin{array}{l}21.9 \\
16.2 \\
18.7\end{array}$ & 0.660 & $\begin{array}{l}70.0 \\
65.0 \\
65.3\end{array}$ & $\begin{array}{l}37.0 \\
38.9 \\
57.2\end{array}$ & $\begin{array}{l}102.9 \\
91.0 \\
73.5\end{array}$ & 0.149 \\
\hline Histology & $\begin{array}{l}\text { Serous } \\
\text { Non-serous }\end{array}$ & $\begin{array}{l}161 \\
80\end{array}$ & $\begin{array}{l}15.9 \\
17.2\end{array}$ & $\begin{array}{l}11.9 \\
13.4\end{array}$ & $\begin{array}{l}19.9 \\
21.0\end{array}$ & 0.536 & $\begin{array}{l}67.3 \\
64.8\end{array}$ & $\begin{array}{l}57.7 \\
56.6\end{array}$ & $\begin{array}{l}76.9 \\
73.0\end{array}$ & 0.916 \\
\hline Lymphadenectomy & $\begin{array}{l}\text { Yes } \\
\text { No }\end{array}$ & $\begin{array}{l}169 \\
72\end{array}$ & $\begin{array}{l}18.0 \\
13.1\end{array}$ & $\begin{array}{l}15.0 \\
11.9\end{array}$ & $\begin{array}{l}20.9 \\
14.2\end{array}$ & 0.577 & $\begin{array}{l}71.1 \\
58.0\end{array}$ & $\begin{array}{l}63.6 \\
48.0\end{array}$ & $\begin{array}{l}78.5 \\
68.0\end{array}$ & 0.481 \\
\hline LN involvement & $\begin{array}{l}\text { Yes } \\
\text { No }\end{array}$ & $\begin{array}{l}105 \\
64\end{array}$ & $\begin{array}{l}18.0 \\
18.7\end{array}$ & $\begin{array}{l}12.3 \\
16.0\end{array}$ & $\begin{array}{l}23.6 \\
21.4\end{array}$ & 0.493 & $\begin{array}{l}75.4 \\
61.7\end{array}$ & $\begin{array}{l}68.8 \\
54.3\end{array}$ & $\begin{array}{l}82.0 \\
69.2\end{array}$ & 0.849 \\
\hline Number of LN & $\begin{array}{l}1-20 \\
21-40 \\
>40\end{array}$ & $\begin{array}{l}13 \\
49 \\
107\end{array}$ & $\begin{array}{l}13.5 \\
20.9 \\
18.7\end{array}$ & $\begin{array}{l}10.0 \\
17.2 \\
15.1\end{array}$ & $\begin{array}{l}16.9 \\
24.6 \\
22.3\end{array}$ & 0.092 & $\begin{array}{l}75.5 \\
71.0 \\
71.1\end{array}$ & $\begin{array}{l}54.0 \\
62.7 \\
58.6\end{array}$ & $\begin{array}{l}96.9 \\
79.2 \\
83.5\end{array}$ & 0.242 \\
\hline $\begin{array}{l}\text { Location of LN } \\
\text { involvement }\end{array}$ & $\begin{array}{l}\text { Pelvic } \\
\text { Paraaortic } \\
\text { Pelvic + paraaortic }\end{array}$ & $\begin{array}{l}17 \\
27 \\
61\end{array}$ & $\begin{array}{l}20.7 \\
21.0 \\
12.1\end{array}$ & $\begin{array}{l}16.4 \\
6.1 \\
9.3\end{array}$ & $\begin{array}{l}24.9 \\
35.8 \\
14.7\end{array}$ & 0.267 & $\begin{array}{l}71.0 \\
74.0 \\
78.0\end{array}$ & $\begin{array}{l}58.3 \\
65.8 \\
68.9\end{array}$ & $\begin{array}{l}83.6 \\
82.1 \\
87.0\end{array}$ & 0.751 \\
\hline $\begin{array}{l}\text { Number of } \\
\text { malignant LN }\end{array}$ & $\begin{array}{l}1-5 \\
6-10 \\
10<\end{array}$ & $\begin{array}{l}61 \\
12 \\
32\end{array}$ & $\begin{array}{l}20.7 \\
11.5 \\
12.1\end{array}$ & $\begin{array}{l}14.9 \\
0 \\
8.5\end{array}$ & $\begin{array}{l}26.4 \\
24.4 \\
15.3\end{array}$ & 0.430 & $\begin{array}{l}71.1 \\
89.0 \\
74.0\end{array}$ & $\begin{array}{l}59.6 \\
78.5 \\
48.1\end{array}$ & $\begin{array}{l}82.5 \\
99.4 \\
99.8\end{array}$ & 0.018 \\
\hline Residual tumour & $\begin{array}{l}\text { R0 } \\
R 1(\leq 1 \mathrm{~cm})\end{array}$ & $\begin{array}{l}62 \\
179\end{array}$ & $\begin{array}{l}25.2 \\
13.9\end{array}$ & $\begin{array}{l}15.5 \\
12.0\end{array}$ & $\begin{array}{l}34.9 \\
15.8\end{array}$ & 0.001 & $\begin{array}{l}78.4 \\
63.0\end{array}$ & $\begin{array}{l}68.4 \\
56.7\end{array}$ & $\begin{array}{l}88.4 \\
69.2\end{array}$ & 0.001 \\
\hline
\end{tabular}

PFS - progression free survival; OS — overall survival; $\mathrm{Cl}$ — confidence interval; $\mathrm{LN}$ - lymph node

determined in OS as the number of malignant LNs increased $(p=0.018)$. However, this effect was not observed in PFS. When the effect of the amount of residual tumour was analysed, the median PFS was 25.2 months in patients who had undergone R0, 13.9 months in patients who had undergone R1 $(p<0.001)$. The overall survival was seen to decrease as the amount of residual tumour increased $(p<0.001)$. In the uni-variate analysis, while there was a significant difference regarding stage and residual tumour $(p<0.05)$, there was also a difference in only stage in the multi-variate analysis $(p<0.05)$. No difference was determined in SLND and LN involvement in either of the two analyses ( $p>0.05$ ) (Tab. 3). When subgroup analysis was performed according to the residual tumour amount, the median PFS was 21 months in SLND patients in the R0 group, 32 months in those who did not (p: 0.057), and 25 months in patients with LN involvement and 21 months in patients without $L N$ involvement (p: 0.917). In terms of OS, it was found that both SLND and LN involvement were not statistically different in the R0 group (p: 0.106 and p: 0.980 , respectively). When we looked at the R1 group, it was seen that both PFS and OS times of SLND and LN involvement were close to each other and there was no statistically significant difference (p: $0.530, \mathrm{p}: 0.711$, p: 0.471 and p: 0.464 , respectively). Survival analysis is given in Table 4 according to the residual tumour amount.

\section{DISCUSSION}

Pelvic and para-aortic lymphadenectomy is a common procedure in ovarian cancer. However, the effect of lymphadenectomy on overall survival has been a subject of debate in different studies. The constant effect of non-pelvic macroscopic tumour on survival has gradually secured its position and stage $3 C$ retro-peritoneal lymph node involvement in FIGO 1988 has been changed in FIGO 2014 and re-defined as stage $3 \mathrm{~A} 1$. FIGO recommends lymphadenectomy due to the likelihood of up-stage in early-stage ovarian cancer [14]. According to the current NCCN guidelines, bulky nodes or suspected lymph nodes should be removed if possible or SLND should be performed in patients who have tumoral nodes of $\geq 2 \mathrm{~cm}$ [15]. Although post-surgery treatment modalities are more standard in ovarian cancer, surgical treatment may vary depending on the spread of the dis- 

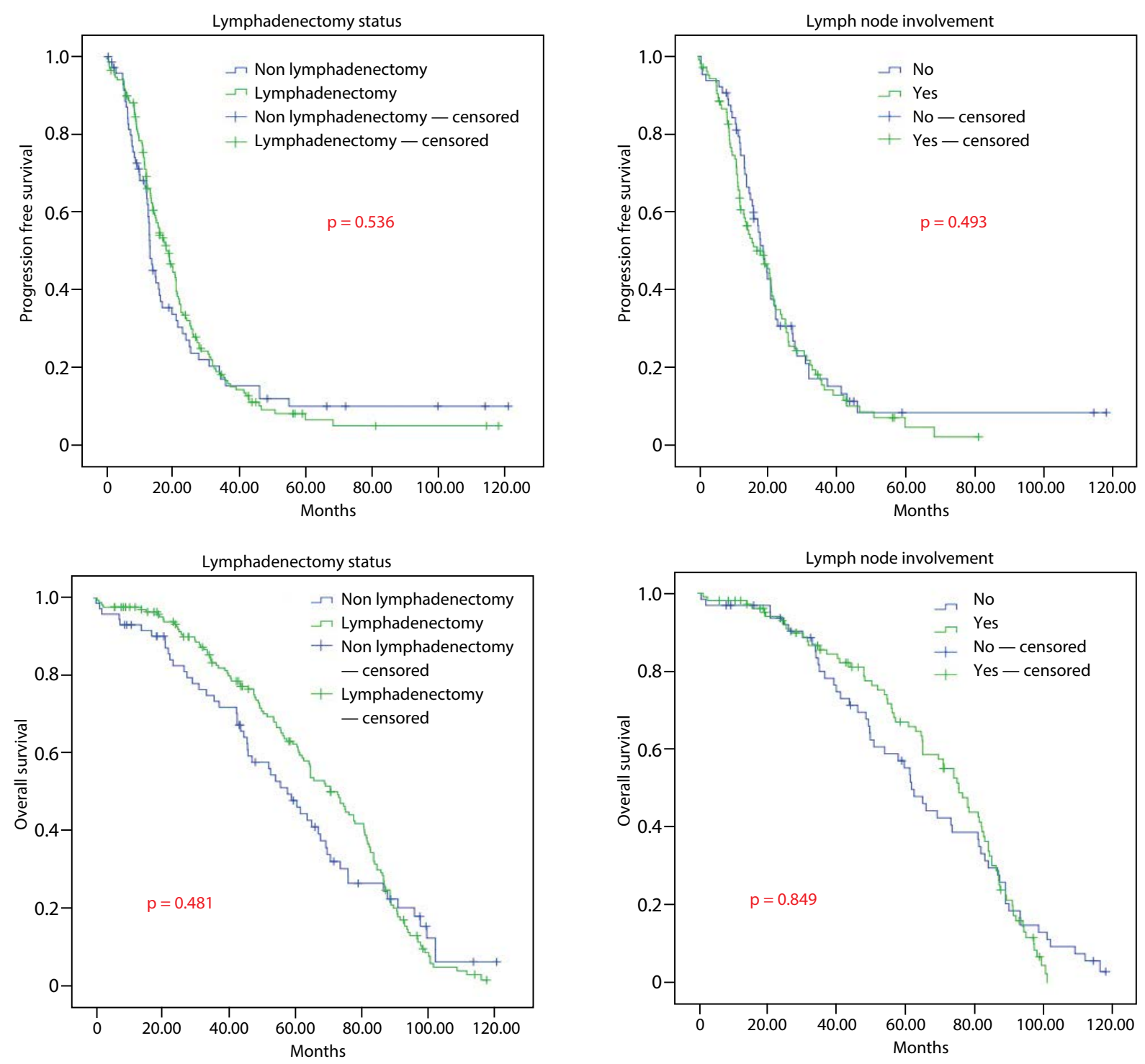

Figure 1. A. Lympadenectomy status and progression free survival; B. Lymp node involvement and progression free survival; C. Lympadenectomy status and overall survival; D. Lymp node involvement and overall survival

\begin{tabular}{|c|c|c|c|c|c|c|c|c|}
\hline & \multicolumn{4}{|c|}{ Uni-variate analysis } & \multicolumn{4}{|c|}{ Multi-variate analysis } \\
\hline & \multirow{2}{*}{ HR } & \multicolumn{2}{|c|}{$95 \% \mathrm{Cl}$} & \multirow{2}{*}{$\mathbf{P}$} & \multirow{2}{*}{ HR } & \multicolumn{2}{|c|}{$95 \% \mathrm{Cl}$} & \multirow{2}{*}{$\mathbf{P}$} \\
\hline & & lower & upper & & & lower & upper & \\
\hline Age & 1.01 & 0.99 & 1.02 & 0.120 & \multirow{3}{*}{3.48} & \multirow{3}{*}{1.64} & \multirow{3}{*}{7.35} & \multirow{3}{*}{0.001} \\
\hline Grade & 0.98 & 0.59 & 1.65 & 0.960 & & & & \\
\hline Stage $(2 b \leq)$ & 4.0 & 2.03 & 7.88 & 0.001 & & & & \\
\hline Lymphadenectomy & 0.89 & 0.65 & 1.22 & 0.480 & \multirow{3}{*}{1.19} & \multirow{3}{*}{0.80} & \multirow{3}{*}{1.76} & \multirow{3}{*}{0.382} \\
\hline LN involvement & 1.03 & 0.55 & 1.54 & 0.850 & & & & \\
\hline Residual tumour & 1.78 & 1.24 & 2.56 & 0.002 & & & & \\
\hline
\end{tabular}

$\mathrm{HR}$ - hazard ratio; $\mathrm{Cl}$ - confidence interval; $\mathrm{LN}$ - lymph node 
Table 4. Progression-free and overall survival analysis of lymphadenectomy and lymph node involvement in patients with complete (R0) and optimal (R1) cytoreduction

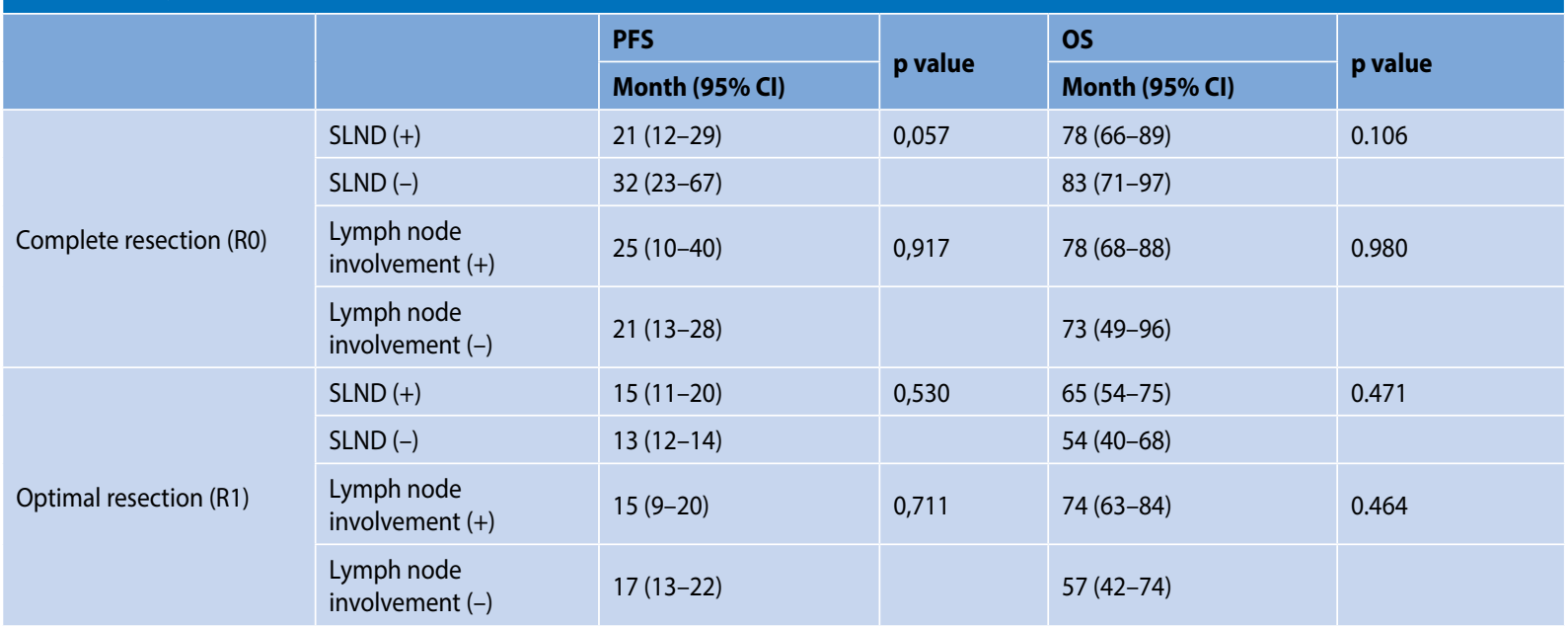

SLND — systemic lymphadenectomy; PFS — progression free survival; OS — overall survival; $\mathrm{Cl}$ - confidence interval

ease and the preference of the surgeon. This is also valid for lymphadenectomy, because surgeons may not wish to add this procedure to the cyto-reductive procedure as challenging complications are more common in patients undergoing lymphadenectomy [10-13].

Lymphadenectomy has been emphasized to be an important prognostic risk factor in previous publications $[6,13]$. Today, it is known that ovarian cancer may progress to lymphatic besides peritoneal spread, and that the presence of lymphatic involvement is associated with a poor prognosis [16]. It has been reported that occult metastases could be overlooked when SLND is not performed, and this could lead to early recurrences due to chemo-resistant disease [17]. Hence, many papers have been published about ovarian cancer and lymphadenectomy, a debatable issue, during the recent two decades. The likelihood of detection of metastatic lymph node is around $60 \%$ in the literature when lymphadenectomy is performed in advanced stage ovarian cancer $[18,19]$. In our study, the number of patients who had undergone SLND and detected to have metastasis was 105 (62.1\%), consistent with the literature. It should be investigated whether the number of removed lymph nodes has a contribution to survival or not. In a retrospective study of Eoh et al., less than 20 lymph nodes were removed in some ovarian cancer patients who had undergone optimal debulking and more than 20 lymph nodes in some others. While removal of more than 20 lymph nodes had a limited contribution to PFS ( $p=0.059)$, it had a great contribution to OS ( $p=0.001)$ [19]. In the Surveillance, Epidemiology and End Results (SEER) database of Zhou et al. [18], while lymphadenectomy was found to be useful in patients in whom $<10$ lymph nodes had been removed and complete resection had been performed $(p=0.017)$, it was shown that it did not contribute to survival in those who had residues of $<1 \mathrm{~cm}$ and $>1 \mathrm{~cm}$ ( $p=0.193, p=0.656$, respectively). In our study, no significant contribution was determined in OS despite having removed a sufficient number of lymph nodes (median $=46$, range 9-95). When analysed according to the number of metastatic lymph nodes, it was found not to have a significant contribution to PFS; however, it had a statistically significant contribution to OS ( $p=0.018$ ). Determining an improvement in survival as the number of removed lymph nodes increases may be expected due to the reduced retro-peritoneal tumoral load. When analyzed according to metastatic lymph node location, we can clearly see that location has no effect on survival. Anyway, pelvic or paraaortic lymph involvement in FIGO staging does not increase the stage. When looking at this situation, it is understood that the main thing is the removal of malignant lymph nodes and/or bulky nodes.

Although SLND is a prognostic risk factor, its contribution to survival is not clear. In a meta-analysis including three randomized controlled and 11 retrospective studies, while there was a difference in PFS in randomized studies, this difference was not observed in retrospective studies. It was found to have a positive effect on OS, both in early stage and advanced stage ovarian cancer. Furthermore, performing LND was associated with low recurrence rates [20]. In the study of Dubois et al. reviewing three randomized controlled studies, performing SLND was shown to significantly contribute to PFS and OS in advanced stage ovarian cancer patients who had undergone complete (R0) debulking [6]. In another meta-analysis, the presence of a significant positive effect in PFS and OS in advanced stage ovarian cancer patients who had undergone SLND was associated with the heterogeneity of the studies [21]. After the LION study, this 
issue continues to be discussed in the literature. In the last published meta-analysis, it was emphasized that systemic lymphadenectomy contributes significantly to the survival of patients who undergo optimal debulking in advanced stage ovarian cancer, but it does not have an advantage in patients who undergo complete resection. In addition, according to the results of only RCTs in this meta-analysis, it was stated that SLND had no effect on survival [22].

Despite the presence of studies indicating that lymphadenectomy has a contribution to survival, some others report no contribution [23]. In the most recent multi-centre randomized controlled study conducted to solve the debate on this issue (LION study), while SLND was performed in 323 out of 647 advanced stage (Stage $2 b-4$ ) ovarian cancer patients who had normal lymph nodes before and during surgery and who had undergone complete resection, it was not performed in 324. The median number of removed lymph nodes was 57 and the rate of lymph node metastasis was $55.7 \%$. The median PFS was 25.5 months for both groups $(p=0.29)$. While the median OS was 65.5 in the SLND group, it was 69.2 in the other group $(p=0.65)$. While the rate of complications was $2.4 \%$ with no contribution, it was $6.5 \%$ in the other group ( $p=0.01)$, and the 60 -day mortality rate was $3.1 \%$ vs $0.9 \%(p=0.049)$ [11]. In our study, while the median PFS was 18 months in patients who had undergone SLND, it was 13.1 months in patients who had not $(p=0.577)$. A similar neutral effect was found in patients who had undergone lymphadenectomy and those who did not have lymph node involvement $(p=0.493)$. This situation shows us that peritoneal spread is at the forefront and more effective on recurrence than lymphatic spread.

While the median OS was 71.1 months in the SLND group in our study, it was 58 months in the group that had not undergone SLND ( $p=0.481)$. No significant difference was determined in OS in the group with lymph node metastasis $(p=0.849)$. In a recent meta-analysis, 2 of the 7 studies that were randomized clinical trials investigated lymphadenectomy in advanced stage ovarian cancer. While lymphadenectomy led to a significant improvement in OS [hazard ratio $(\mathrm{HR})=0.64 ; 95 \%$ confidence interval $(\mathrm{Cl})$ : 0.49-0.84, $\mathrm{p}<0.01$ ], this effect was not seen in PFS $(\mathrm{HR}=0.89,95 \% \mathrm{Cl}$ : $0.69-1.15, p=0.38$ ). In the subgroup analysis, it was reported that it did not affect the PFS ( $\mathrm{HR}=1.09,95 \% \mathrm{Cl}: 0.91-1.30$, $\mathrm{p}=0.33)$ and $\mathrm{OS}(\mathrm{HR}=0.81,95 \% \mathrm{Cl}: 0.66-1.00, \mathrm{p}=0.05)$ [24]. In the uni-variate analysis in our study, although the mortality risk decreased in patients who had undergone SLND, there was no statistically significant difference $(H R=0.89$; 95\% Cl: 0.65-1.22, $\mathrm{p}=0.480$ ).

In addition, in another recent meta-analysis in which 4 RCTs were included, it was emphasized that systemic lymphadenectomy did not contribute to both PFS and OS in advance stage ovarian cancer. In addition, it was shown that severe complications were more common in patients who underwent SLND [25] So even methanalysis still offers controversial results on this matter.

The effect of systemic lymphadenectomy on survival is still unclear according to the amount of residual tumor. There are studies showing that SLND has a significant effect on survival in patients with complete resection, but SLND does not have an effect on patients with optimal and sub-optimal debulking $[17,22]$. When the opinion that SLND should be added to surgery if complete (R0) debulking is to be performed, a prospective randomized LION study was designed to reveal the effect of lymphadenectomy in patients with RO [13]. According to the results of our own study, SLND and lymph node involvement in both R0 (complete) and R1 (optimal) debulking patients did not statistically contribute to short and long term survival. We see that these results are similar to the results of the most recently published LION study.

The present study has some limitations. Bias could be present in the patient selection due to the retrospective design of the study. However, the clinical and prognostic risk factors were attempted to be equal in both groups. Standardization of medical therapies was not known, particularly with regard to target therapy. The study could have included some prognostic risk factors such as the amount of ascites at the time of first admission, the platinum status and the post-operative complications.

\section{CONCLUSIONS}

In conclusion, it was found that performing systemic lymphadenectomy had no effect on both progressive and overal survival. It should be kept in mind that the increasing number of malignant lymph nodes removed could have a therapeutic effect in OS. Large numbers of randomized clinical trials are required to enlighten this debatable issue that has been continuing, particularly in the recent two decades.

\section{Conflict of interest}

None.

\section{REFERENCES}

1. Torre LA, Trabert B, DeSantis CE, et al. Ovarian cancer statistics, 2018. CA Cancer J Clin. 2018; 68(4): 284-296, doi: 10.3322/caac.21456, indexed in Pubmed: 29809280.

2. Bray F, Ferlay J, Soerjomataram I, et al. Global cancer statistics 2018 : GLOBOCAN estimates of incidence and mortality worldwide for 36 cancers in 185 countries. CA Cancer J Clin. 2018; 68(6): 394-424, doi: 10.3322/caac.21492, indexed in Pubmed: 30207593.

3. Burger RA, Brady MF, Bookman MA, et al. Gynecologic Oncology Group. Incorporation of bevacizumab in the primary treatment of ovarian cancer. N Engl J Med. 2011; 365(26): 2473-2483, doi: 10.1056/NEJMoa1104390, indexed in Pubmed: 22204724.

4. Perren TJ, Swart AM, Pfisterer J, et al. ICON7 Investigators. A phase 3 trial of bevacizumab in ovarian cancer. N Engl J Med. 2011; 365(26): 24842496, doi: 10.1056/NEJMoa1103799, indexed in Pubmed: 22204725. 
5. Ayhan A, Gultekin M, Dursun P, et al. Metastatic lymph node number in epithelial ovarian carcinoma: does it have any clinical significance? Gynecol Oncol. 2008; 108(2):428-432, doi: 10.1016/j.ygyno.2007.09.014, indexed in Pubmed: 18249232.

6. Bois Adu, Quinn M, Thigpen T, et al. 2004 consensus statements on the management of ovarian cancer: final document of the 3rd International Gynecologic Cancer Intergroup Ovarian Cancer Consensus Conference (GCIG OCCC 2004). Annals of Oncology. 2005; 16: viii7-viii12, doi: 10.1093/annonc/mdi961.

7. Slavchev S, Kostov S, Strashilov S, et al. Relation between type of hysterectomy and survival rate in patients with ovarian cancer single-center study. Prz Menopauzalny. 2020; 19(3): 111-116, doi: 10.5114/pm.2020.99572, indexed in Pubmed: 33100945.

8. du Bois A, Reuss A, Harter P, et al. Arbeitsgemeinschaft Gynaekologische Onkologie Studiengruppe Ovarialkarzinom, Groupe d'Investigateurs Nationaux pour l'Etude des Cancers Ovariens. Potential role of lymphadenectomy in advanced ovarian cancer: a combined exploratory analysis of three prospectively randomized phase III multicenter trials. J Clin Oncol. 2010; 28(10): 1733-1739, doi: 10.1200/JCO.2009.25.3617, indexed in Pubmed: 20194855.

9. Harter $\mathrm{P}, \mathrm{G}$ nauert $\mathrm{K}$, Hils $\mathrm{R}$, et al. Pattern and clinical predictors of lymph node metastases in epithelial ovarian cancer. Int J Gynecol Cancer. 2007; 17(6): 1238-1244, doi: 10.1111/j.1525-1438.2007.00931.x, indexed in Pubmed: 17433064

10. Siegel R, Ma J, Zou Z, et al. Cancer statistics, 2014. CA Cancer J Clin. 2014; 64(1): 9-29, doi: 10.3322/caac.21208, indexed in Pubmed: 24399786.

11. Harter P, Sehouli J, Lorusso D, et al. A Randomized Trial of Lymphadenectomy in Patients with Advanced Ovarian Neoplasms. N Engl J Med. 2019; 380(9): 822-832, doi: 10.1056/NEJMoa1808424, indexed in Pubmed: 30811909.

12. Aletti GD, Dowdy S, Podratz KC, et al. Role of lymphadenectomy in the management of grossly apparent advanced stage epithelial ovarian cancer. Am J Obstet Gynecol. 2006; 195(6): 1862-1868, doi: 10.1016/j. ajog.2006.06.068, indexed in Pubmed: 17132488.

13. Panici PB, Maggioni A, Hacker N, et al. Systematic aortic and pelvic lymphadenectomy versus resection of bulky nodes only in optimally debulked advanced ovarian cancer: a randomized clinical trial. J Natl Cancer Inst. 2005; 97(8): 560-566, doi: 10.1093/jnci/dji102, indexed in Pubmed: 15840878.

14. Prat J. FIGO Committee on Gynecologic Oncology. Staging classification for cancer of the ovary, fallopian tube, and peritoneum. Int J Gynaecol Obstet. 2014; 124(1): 1-5, doi: 10.1016/j.ijgo.2013.10.001, indexed in Pubmed: 24219974.
15. NCCN guideline version4 2017. Epithelial ovarian cancer/Fallopian Tube cancer/Primary peritoneal cancer.

16. PaikES, Lee YY, Lee EJ, et al. Survival analysis of revised 2013 FIGO staging classification of epithelial ovarian cancer and comparison with previous FIGO staging classification. Obstet Gynecol Sci. 2015; 58(2): 124-134, doi: 10.5468/ogs.2015.58.2.124, indexed in Pubmed: 25798426.

17. Berek JS. Lymph node-positive stage IIIC ovarian cancer: a separate entity? Int J Gynecol Cancer. 2009; 19 Suppl 2: S18-S20, doi: 10.1111/IGC.0b013e3181bf8111, indexed in Pubmed: 19955908.

18. Zhou J, Zhang WW, Zhang QH, et al. The effect of lymphadenectomy in advanced ovarian cancer according to residual tumor status: A population-based study. Int J Surg. 2018; 52: 11-15, doi: 10.1016/j. ijsu.2018.02.006, indexed in Pubmed: 29432972.

19. Eoh KJ, Lee JY, Yoon JW, et al. Role of systematic lymphadenectomy as part of primary debulking surgery for optimally cytoreduced advanced ovarian cancer: Reappraisal in the era of radical surgery. Oncotarget. 2017; 8(23): 37807-37816, doi: 10.18632/oncotarget.13696, indexed in Pubmed: 27906676.

20. Zhou J, Shan G, Chen Y. The effect of lymphadenectomy on survival and recurrence in patients with ovarian cancer: a systematic review and meta-analysis. Jpn J Clin Oncol. 2016; 46(8): 718-726, doi: 10.1093/jjco/hyw068, indexed in Pubmed: 27272175.

21. Gao J, Yang $X$, Zhang Y. Systematic lymphadenectomy in the treatment of epithelial ovarian cancer: a meta-analysis of multiple epidemiology studies. Jpn J Clin Oncol. 2015; 45(1): 49-60, doi: 10.1093/jjco/hyu175, indexed in Pubmed: 25387732

22. Chiyoda T, Sakurai M, Satoh T, et al. Lymphadenectomy for primary ovarian cancer: a systematic review and meta-analysis. J Gynecol Oncol. 2020; 31(5): e67, doi: 10.3802/jgo.2020.31.e67, indexed in Pubmed: 32808497.

23. Abe A, Furumoto $H$, Irahara $M$, et al. The impact of systematic para-aortic and pelvic lymphadenectomy on survival in patients with optimally debulked ovarian cancer. J Obstet Gynaecol Res. 2010; 36(5): 1023-1030, doi: 10.1111/j.1447-0756.2010.01274.x, indexed in Pubmed: 21058437.

24. Wang Y, Ren F, Song Z, et al. Prognostic Significance of Systematic Lymphadenectomy in Patients With Optimally Debulked Advanced Ovarian Cancer: A Meta-Analysis. Front Oncol. 2020; 10: 86, doi: 10.3389/fonc.2020.00086, indexed in Pubmed: 32117740.

25. Lin Q Liu W, Xu S, et al. The value of systematic lymphadenectomy during debulking surgery in the treatment of ovarian cancer: a meta-analysis of randomized controlled trials. J Ovarian Res. 2020; 13(1): 56, doi: 10.1186/s13048-020-00653-4, indexed in Pubmed: 32384898. 